\title{
The Art of Goodbye: Medicare Covers Advance Care Planning ${ }^{1}$
}

\author{
Lynda Spence ${ }^{2}$
}

This document is part of a series which addresses end-oflife concerns, entitled The Art of Goodbye.

\section{Overview}

In the early 1960s, only half of older adults in the United States had health insurance. For uninsured older adults, coverage was expensive. It was determined at that time that neither income nor medical history should be a determinant of coverage. A system designed to help manage health risks for aging adults was needed. Medicare was created under Social Security in 1965 and introduced as government-sponsored health insurance for individuals 65 and older. Currently, 57 million individuals, or $16 \%$ of the total population of the United States, are enrolled in Medicare (Henry J. Kaiser Family Foundation, 2017).

Throughout the years, Medicare has expanded to bring the program in line with changing times and needs.

\section{Patient Self-Determination Act of 1990}

An example of legislation passed since the program's inception is the Patient Self-Determination Act of 1990 (PSDA). This act requires that a patient's right to self-determination in health care decisions is communicated and protected (Kelley, 1995). According to the PSDA, at the time of admission, most health care institutions are required to (1) provide an explanation of decision-making rights in the respective location (state), (2) ask if there is an advance directive, and if there is, note that fact in the medical records, (3) educate staff and community about ADs, and (4) not make unjust or prejudicial distinctions based on the presence or absence of an AD (American Bar Association, 2018).

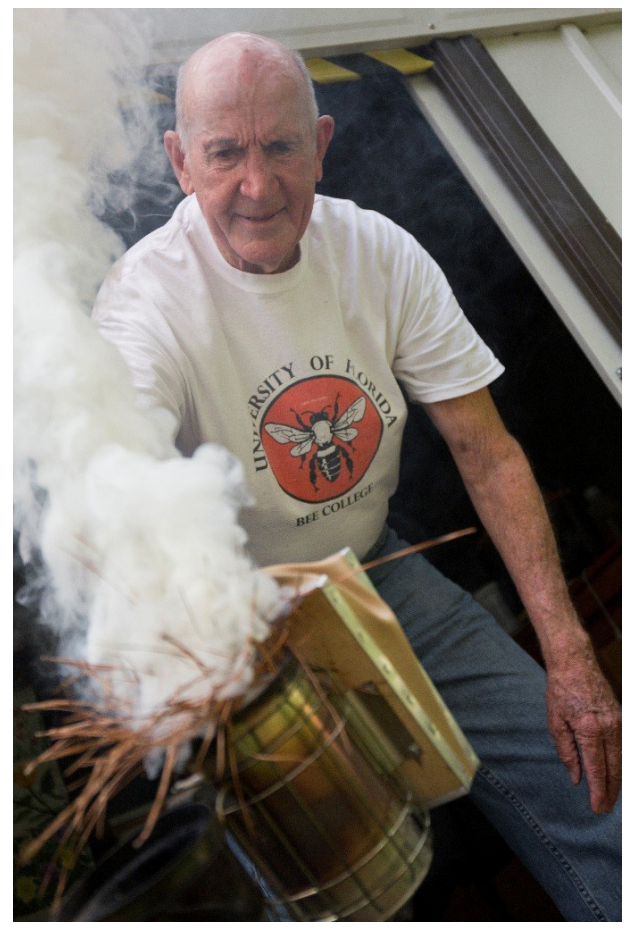

Figure 1. Roughly 10,000 baby boomers will turn 65 today, and about 10,000 more will cross that threshold every day for the next 19 years (Pew Research Center, 2010).

Credits: UF/IFAS

1. This document is FCS3340, one of a series of the Department of Family, Youth and Community Sciences, UF/IFAS Extension. Original publication date July 2018. Visit the EDIS website at http://edis.ifas.ufl.edu.

2. Lynda Spence, Extension agent II, UF/IFAS Extension Marion County; UF/IFAS Extension, Gainesville, FL 32611.

The Institute of Food and Agricultural Sciences (IFAS) is an Equal Opportunity Institution authorized to provide research, educational information and other services

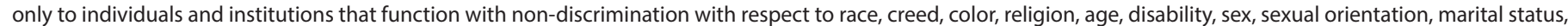

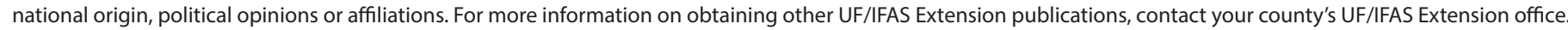
U.S. Department of Agriculture, UF/IFAS Extension Service, University of Florida, IFAS, Florida A \& M University Cooperative Extension Program, and Boards of County Commissioners Cooperating. Nick T. Place, dean for UF/IFAS Extension. 


\section{Advance Care Planning}

Advance care planning (ACP) became a covered service in January 2016. This newly covered service addresses older adults' right to be covered for discussions about end-of-life planning with their health care provider. These conversations can address important decisions that will lead to a patient's control over the type of care they receive and when they receive it (Centers for Medicare \& Medicaid Services, 2016).

Advance care planning supports patients' efforts to make better and informed decisions about end-of-life care ahead of time. ACP coverage reimburses physicians for counseling patients about health care options, particularly before the patients become physically or mentally incapable of making decisions. Advantages of advance care planning include, but are not limited to:

1. The chance to consider preferences, make decisions, and plan outside of a crisis, diagnosis, or terminal illness.

2. The opportunity to learn about health care options available for end-of-life care.

3. The ability to determine which types of care fit personal preferences (Centers for Medicare \& Medicaid Services, 2016).

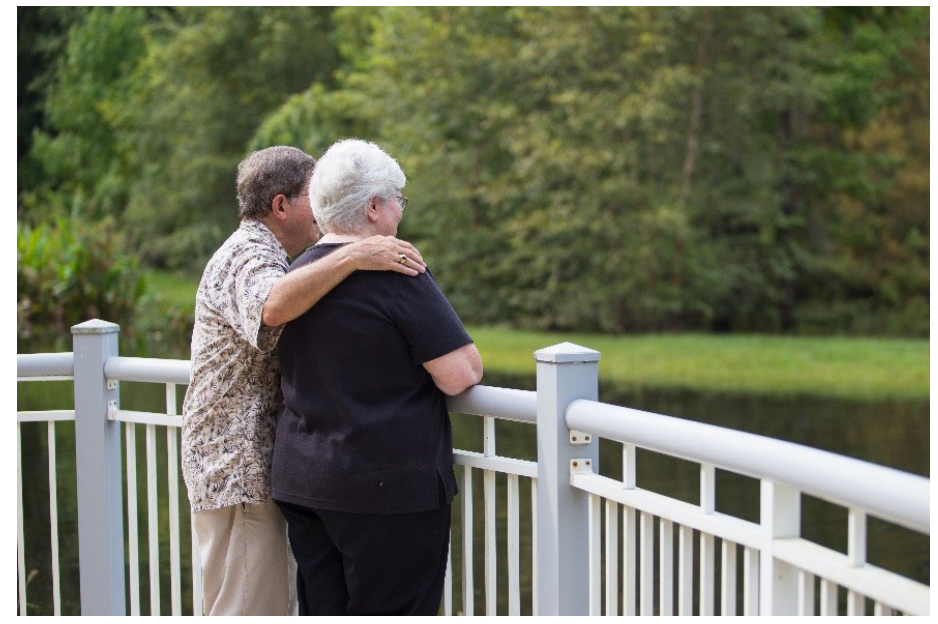

Figure 2.

Credits: UF/IFAS

Medicare-covered advance care planning is covered as a separate service provided by physicians and other qualifying health professionals. ACP can be provided in medical offices and facility settings, including hospitals. When the service is provided during the annual wellness visit, it is billed to Medicare separately. In these cases, the patient incurs no cost for the service (Henry J. Kaiser Family Foundation, 2015).

\section{Communicating About Advance Care Planning}

Medical conditions can be complex and are unique to each patient's circumstances. ACP is intended to open lines of communication with practitioners and loved ones before a crisis occurs. Not everything will be covered in a single conversation. Effective communication about complicated matters such as end-of-life planning translates into a series of conversations over the course of years. The process of advance care planning is meant to help individuals find the right answers and preserve the patient's dignity. ACP includes early conversations between patients and practitioners:

\section{During wellness visits}

2. During diagnoses of serious illnesses

\section{Before illness progresses}

\section{During course of treatment (Henry J. Kaiser Family} Foundation, 2015)

Steps must be taken to ensure patients are counseled. Sometimes reluctance or pushback from either the patient or health care provider makes initiating a conversation difficult. A 2006 study of 95 health care providers who said they felt hesitant bringing up end-of-life-care reported:

- $21 \%$ of patients were not ready to talk about the issue

- $11 \%$ felt uncomfortable bringing it up

- $9 \%$ worried about destroying the sense of hope

- $8 \%$ reported time constraints (Rhodes, Tindall, Xuan, Paulk, \& Halm, 2014)

Recently, there have been signs of increased openness to discussions about death as a natural part of life and the human condition (Smith \& Spence, 2016). Compared to respondents in a 2006 study, a 2013 cohort of health care providers reported they received more lectures about endof-life communication and watched an attending physician have end-of-life discussions more often. Over half of the respondents felt they were able to have open and honest discussions with patients and families (Rhodes, Tindall, Xuan, Paulk, \& Halm, 2014).

Nonprofits such as VitalTalk (http://vitaltalk.org/) have been founded to facilitate the development of advanced 
communication skills among health care providers. Academia is also doing its part. Curricula, courses, and faculty training courses are focused on balancing honesty with empathy when discussing serious illness and end-of-life care. Examples of professional development for health care providers include:

- OncoTalk—oncologists (Epner \& Baile, 2014)

- GeriTalk-geriatricians (Kelley et al., 2012)

- NephroTalk-renal specialists (Schell \& Arnold, 2012)

- IntensiveTalk-intensive care specialists (Graham, 2014)

Innovative clinical models to implement these discussions earlier in the care process have been explored. Research on evolving theory in health care practice found that strategies providers can put into practice for the productive enhancement of end-of-life discussions are connected to:

- Physicians' interpersonal communication skills

- Patient-centered models of care

- A focus on the quality of life (Larson \& Tobin, 2000)

\section{A Brighter Future}

The research is encouraging. Studies show that end-of life communication and care are improving, and more goals aimed at better care are within reach. Medical and social care communities are encouraged by new methodologies of engaging patients and families in advance care planning and shared decision-making.

The Institute of Medicine (IOM) committee recommends further exploration into patient communication and advance care planning, professional education and development, payment systems and policies, and public engagement and education (National Academy of Sciences, 2014).

In summary, end-of-life conversations must become a routine and structured part of health care. Advance care planning is best viewed as one component in a series of ongoing end-of-life discussions (Larson \& Tobin, 2000).

\section{References}

American Bar Association. (2018). Health care advance directives. Law for Older Americans. Accessed on May 24, 2018. https://www.americanbar.org/groups/public_education/resources/law_issues_for_consumers/patient_self_determination_act.html
Centers for Medicare \& Medicaid Services. (2016). Advance care planning. Accessed on May 24, 2018. https://www. $\mathrm{cms}$.gov/Outreach-and-Education/Medicare-LearningNetwork-MLN/MLNProducts/Downloads/AdvanceCarePlanning.pdf

Centers for Medicare \& Medicaid Services. (2015). On its $50^{\text {th }}$ anniversary, more than 55 million Americans covered by Medicare. CMS.gov. Accessed on April 30, 2016. https:// www.cms.gov/Newsroom/MediaReleaseDatabase/Pressreleases/2015-Press-releases-items/2015-07-28.html

Epner, D. E. \& Baile, W. F. (2014). Difficult conversations: Teaching medical oncology trainees communication skills one hour at a time. Acad. Med., 89(4), 578-584.

Graham, Judith. (2014). IOM report calls for transformation of end-of-life care. JAMA. Accessed on May 24, 2018. https://jamanetwork.com/journals/jama/ fullarticle/1930814?utm_source=Silverchair\%20Information\%20Systems\&utm_medium =email\&utm_campaign=M ASTER:JAMALatestIssueTOCNotification11/11/2014

Henry J. Kaiser Family Foundation. (2015). 10 FAQs: Medicare's role in end-of-life care. Accessed on April 21, 2016. http://files.kff.org/attachment/ fact-sheet-10-faqs-medicares-role-in-end-of-life-care

Henry J. Kaiser Family Foundation. (2017). Medicare Advantage. Medicare. Accessed on April 30, 2016. https:// www.kff.org/medicare/fact-sheet/medicare-advantage/

Kelley, A. S., Back, A. L., Arnold, R. M., Goldberg, G. R., Lim, B. B., Litrivis, E., Smith, C. B., \& O’Neill, L. B. (2012). Geritalk: Communication skills training for geriatrics and palliative medicine fellows. J. Am. Geriatr. Soc., 60(2), 332-337.

Kelley, K. (1995). The Patient Self-Determination Act: A matter of life and death. Physician Assist., 19(3), 49, 53-6, 59-60.

Larson, D. G. \& Tobin, D. R. (2000). End-of-life conversations: Evolving practice and theory. JAMA, 284(12), 1573-1578. doi: 10.1001/jama.284.12.1573.

National Academy of Sciences. (2014). Dying in AmericaImproving quality and honoring individual preferences near the end of life. Institute of Medicine of the National Academies. Accessed on May 24, 2018. http://nationalacademies.org/hmd/ /media/Files/Report\%20Files/2014/EOL/ Report\%20Brief.pdf 
Pew Research Center. (2010). Baby boomers retire. Pew

Research Center. Accessed on July 25, 2016. http://www.pewresearch.org/fact-tank/2010/12/29/baby-boomers-retire/

Rhodes, R., Tindall, K., Xuan, L., Paulk, M. E., \& Halm, E. A. (2014). Communication about advance directives and end-of-life care options among internal medicine residents. American Journal of Hospice and Palliative Care, 262-268.

Schell, J. O. \& Arnold, R. M. (2012). NephroTalk: Communication tools to enhance patient-centered care. Semin. Dial., 25(6), 611-616.

Smith, S. \& Spence, L. (2016). The Art of Goodbye: Why People Are Talking About the End of Life. FCS3337.

Gainesville: University of Florida Institute of Food and Agricultural Sciences. http://edis.ifas.ufl.edu/fy1468 